\title{
Epstein-Barr virus DNA in nasopharyngeal carcinomas from Chinese patients in Hong Kong
}

\author{
P Dickens, G Srivastava, S L Loke, C W Chan, Y T Liu
}

\begin{abstract}
Aims: To investigate the presence of Epstein-Barr virus (EBV) in cases of nasopharyngeal carcinoma (NPC) in Chinese patients living in Hong Kong. Methods: Nasopharyngeal biopsy specimens, formalin fixed and parafin wax embedded, from 24 patients, eight with undifferentiated nasopharyngeal carcinoma, eight with well differentiated squamous carcinoma, and eight showing normal tissue histology, were analysed for the presence of Epstein-Barr virus (EBV) DNA by slot-blot hybridisation on extracted unamplified DNA, and also after amplification of $\mathrm{EBV}$ specific sequences by the polymerase chain reaction (PCR).

Results: DNA slot-blot analysis showed viral DNA in all the undifferentiated, five of the well differentiated tumours, and none of the normal biopsy specimens. PCR studies confirmed positivity in the eight undifferentiated tumours, but six of the well differentiated tumours and three of the normal biopsy specimens showed viral DNA by this method, illustrating its greater sensitivity.

Conclusions: EBV genome is present in appreciable copy number in most cases of well differentiated NPC in Chinese patients in Hong Kong.
\end{abstract}

Well differentiated keratinising nasopharyngeal carcinoma (NPC) (WHO type 1$)^{1}$ is much rarer than the undifferentiated type (WHO type 3) in high incidence areas such as Hong Kong. It accounts for about $2 \%$ of NPC cases seen in our department. Probably because of the paucity of cases, the relation of EpsteinBarr virus (EBV) to this tumour has been less frequently studied. Patients with this form of NPC show EBV antibody titres similar to those of control populations, ${ }^{2}$ in contrast to the raised titres seen in patients with the undifferentiated variety. Although EBV serology is not helpful in the diagnosis of this tumour, molecular biological techniques can be used to study the relation between the tumour and the virus. The aim of this study was to determine if the EBV

Sequences of oligonucleotide primers and probe used for the amplification of EBV DNA

\begin{tabular}{lll}
\hline Sequence $\left(5^{\prime}>3^{\prime}\right)$ & Size of amplified product $(b p)$ \\
\hline A & CCAGAGGTAAGTGGACTT (18 mer) & 122 \\
B & GACCGGTGCCTTCTTAGG (18 mer) & \\
Probe: & TTCTGCTAAGCCCAAC (16 mer) & \\
\hline
\end{tabular}

genome could be detected in well differentiated NPC in Chinese patients in Hong Kong using DNA slot-blot hybridisation and the polymerase chain reaction (PCR) on archival formalin-fixed paraffin wax embedded tissue.

\section{Methods}

\section{Selection of cases}

Eight cases of undifferentiated nasopharyngeal carcinoma conforming to WHO type 3 criteria, eight cases of well differentiated keratinising squamous carcinoma (WHO type 1), and eight normal nasopharyngeal biopsy specimens were selected from the files of the Department of Pathology, University of Hong Kong. The slides were reviewed and the diagnosis and typing of the malignant biopsy specimens confirmed. Care was taken that these consisted almost entirely of tumour with a minimal amount of lymphoid tissue or nasopharyngeal mucosa present.

\section{DNA slot-blot hybridisation analysis}

Two sections $16 \mu \mathrm{m}$ thick were cut from each sample and dewaxed. The genomic DNA was extracted using proteinase $K$ and denatured DNA was slot-blotted on a nylon membrane. ${ }^{34}$ The presence of EBV genome was detected using a ${ }^{32}$ P-labelled 3. 1 kilobase B95-8 internal repeat $\mathrm{BamW}$ probe with hybridisation and washing conditions as reported. ${ }^{34}$

\section{PCR Analysis}

The oligonucleotide primers used to amplify EBV DNA were within the first internal repeat (IR1) fragment of EBV DNA from base 1399 to 1520. The oligonucleotide probe spans the intervening region within the first internal repeat (IR1) from base 1424 to 1439 (table). DNA amplification was carried out using the DNA amplification reagent kit with native Taq DNA polymerase (Gene Amp, Perkin Elmer Cetus) using conditions reported previously. ${ }^{6}$ The amplified products were analysed by Southern blotting of the gel followed by probing of the membrane with ${ }^{32} \mathrm{P}$-labelled oligomeric probe specific for amplified EBV DNA. The hybridisation and washing conditions were as previously reported. ${ }^{6}$ DNA extracted from EBV-infected Burkitt's lymphoid cell line, Raji, was used as a positive control. SiHa cell line DNA was the negative control. Raji and SiHa cell lines were obtained from the American Tissue Culture Collection.

\section{Results and discussion}

The results of DNA slot-blot hybridisation for the presence of EBV genome using unamplified 


\section{WELL-DIFFERENTIATED NPC}

$\begin{array}{llllllll}1 & 2 & 3 & 4 & 5 & 6 & 7 & 8\end{array}$

\section{UNDIFFERENTIATED NPC}

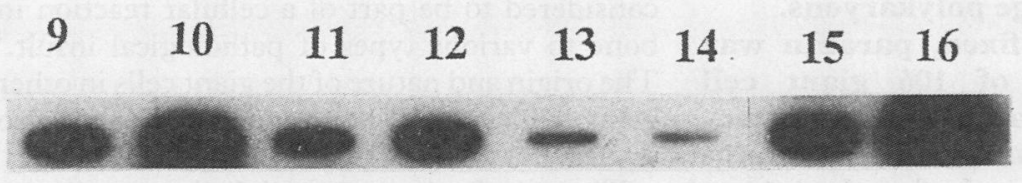

\section{NORMAL NASOPHARYNGEAL BIOPSY}

$\begin{array}{llllllll}17 & 18 & 19 & 20 & 21 & 22 & 23 & 24\end{array}$

Figure 1 Results of the DNA slot-blot hybridisation for the presence of EBV genome using unamplified DNA samples.

\section{WELL-DIFFERENTIATED NPC}

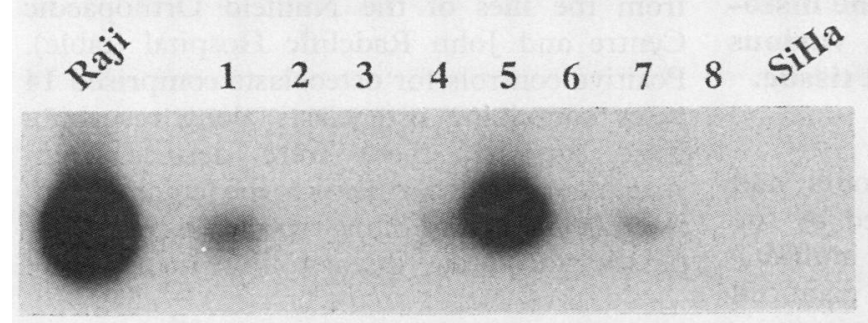

UNDIFFERENTIATED NPC

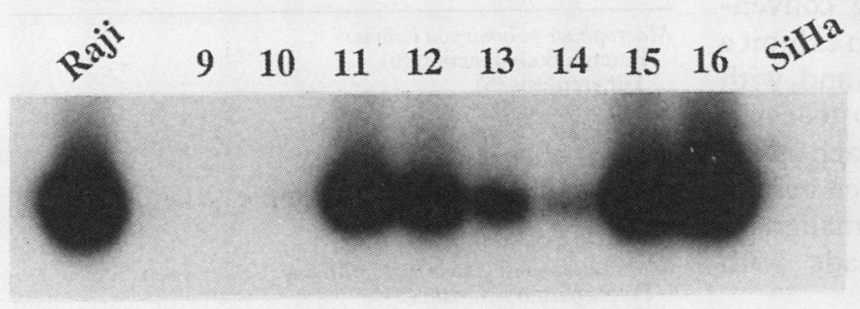

NORMAL NASOPHARYNGEAL BIOPSY

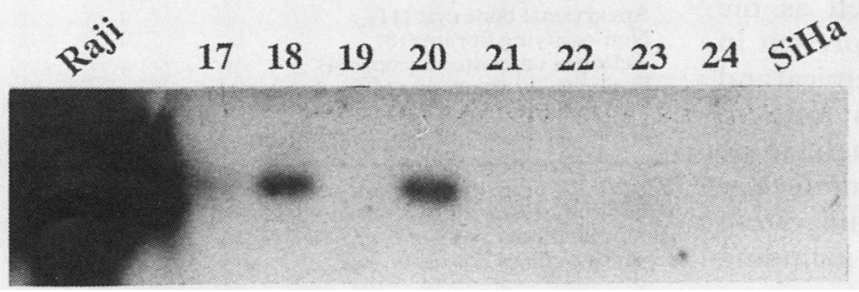

Longer Exposure 26 Longer Exposure

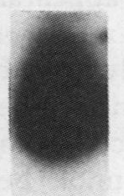

Figure 2 Results of the Southern blot hybridisation of the PCR amplified products.
DNA showed viral DNA in all eight cases of undifferentiated NPC, five of the well differentiated cases (cases 1, 4, 5, 6 and 7) but none of the normal biopsy samples (fig 1). The PCR analysis showed similar results in the undifferentiated cases but one additional well differentiated tumour (case 2) was positive and three of the normal biopsy specimens (cases 17, 18 and 20) showed the presence of EBV DNA (fig 2).

The association of undifferentiated NPC with EBV is well established. Using DNA in situ hybridisation, the viral genome has been demonstrated in the tumour cells. ${ }^{78}$ The well differentiated form of NPC has also been shown to contain EBV, although in very low copy number, by direct Southern blotting using frozen biopsy samples from Caucasian patients. ${ }^{9}$ Our results, using paraffin wax embedded tissue from Asians, indicate that even with the relatively simple technique of DNA slot-blot hybridisation EBV DNA can be readily detected in most cases of well differentiated NPC whereas normal biopsy specimens are consistently negative and undifferentiated NPC cases are consistently positive (as expected). The PCR analysis confirmed the slot-blot findings and the greater sensitivity of this technique would explain the finding of EBV DNA in one additional case of well differentiated NPC and in three of the normal biopsy specimens. This latter result is consistent with a previous report of EBV DNA detection in exfoliated nasopharyngeal cells from normal Chinese subjects who have normal ranges of EBV antibody titres. ${ }^{10}$ The negativity of the eight normal samples by slot-blotting suggests a very low copy number in these biopsy specimens.

We conclude that EBV DNA is present in most cases of well differentiated NPC in Chinese patients in Hong Kong and in appreciable copy number, although not as high as in the undifferentiated tumours. This suggests that, regardless of the histological type, NPC is an EBV-associated malignancy.

This work was supported by grants from the University and Polytechnic Grants Committee and the Wing Lung Bank. We Presing the EBV BamW genomic probe.

1 Shanmugaratman K, Sobin L. Histological typing of upper respiratory tract tumours. Int Typ Tumors 1978;19:32-3. 2 Pearson GR, Weiland LH, Neel HB, Taylor W, Earle J, Mulroney SE. Application of Epstein-Barr (EBV) serology to the diagnosis of North American nasopharynserology to the diagnosis of North Am

3 Loke SL, Ma L, Srivastava G, Lo I, Bird CC. Human papillomavirus types $6,11,16$ and 18 are not detectable in squamous cell carcinoma of the oesophagus. J Clin Pathol 1990;43:902-12.

4 Dickens P, Srivastava G, Loke SL, Larkin S. Human papillomavirus 6,11 and 16 in laryngeal papillomas. $J$ Pathol 1991;165:243-6.

5 Cheung A, Kieff E. Long internal direct repeat in EBV DNA. J Virol 1982;44(1):286-94.

6 Dickens P, Srivastava G, Liu YT. Human papillomavirus $16 / 18$ and nasopharyngeal carcinoma. J Clin Pathol 1992;45:81-2.

7 ung Epstein-Barr virus markers in nasopharyngeal carcinoma Epstein-Barr virus markers in nas.

8 Weiss LM, Movahed LA, Butler AE, et al. Analysis of lymphoepithelioma and lymphoepithelioma-like carcinlymphoepithelioma and lymphoepithelioma-like carcinomas for Epstein-Barr viral genomes by

9 Raab-Traub N, Flynn K, Pearson G, et al. The differenRaab-Traub N, Flynn K, Pearson G, et al. The differen-
tiated form of nasopharyngeal carcinoma contains tiated form of nasopharyngeal carcinoma contain

10 Desgranges C, Pi GH, Bornkamm GW, Legrand C, Zeng Y, de The G. Presence of EBV DNA sequences in nasopharyngeal cells of individuals without IgA-VCA antibodies. Int J Cancer 1983;32:543-5. 